\title{
Low-dose bortezomib increases the expression of NKG2D and DNAM-1 ligands and enhances induced NK and yס T cell- mediated Iysis in multiple myeloma
}

\author{
Chao Niu ${ }^{1, *}$, Haofan Jin ${ }^{1, *}$, Min Lii,*, Shan Zhu ${ }^{2}$, Lei Zhou ${ }^{1}$, Feng Jin ${ }^{1,3}$, Yulai Zhou ${ }^{3}$, \\ Dongsheng $X u^{1}$, Jianting $X_{u^{1}}$, Lianjing $Z_{h a o}{ }^{1}$, Shanshan Hao ${ }^{1,4}$, Wei Li $^{1}$, Jiuwei Cui ${ }^{1}$ \\ ${ }^{1}$ Cancer Center, The First Hospital of Jilin University, Changchun 130021, China \\ ${ }^{2}$ Institute of Translational Medicine, The First Hospital of Jilin University, Changchun 130021, China \\ ${ }^{3}$ College of Pharmacy, Jilin University, Changchun 130021, China \\ ${ }^{4}$ Department of Hematology, Taian Central Hospital, Taian 271000, China \\ "These authors contributed equally to this work as co-first authors \\ Correspondence to: Wei Li, email: drweili@yahoo.com \\ Jiuwei Cui, email: cuijw@jlu.edu.cn
}

Keywords: bortezomib, multiple myeloma, natural killer cells, gamma-delta $T$ cells

Received: September 24, 2016

Accepted: December 08, 2016

Published: December 16, 2016

\begin{abstract}
Multiple myeloma (MM) is an incurable hematological malignancy, although bortezomib has markedly improved its outcomes. Growing clinical evidence indicates that enhancing induced natural killer (NK) or yठ T cells for infusion is useful in the treatment of MM. However, whether combination treatment with bortezomib and induced NK and Yठ T cells further improves outcomes in MM, and how the treatments should be combined, remain unclear. Herein, we found that low-dose bortezomib did not suppress the viability of induced NK and yठ T cells, but did induce MM cell apoptosis. Importantly, low-dose bortezomib increased the expression of NKG2D and DNAM-1 ligands on MM cells, which sensitized the multiple myeloma cells to lysis by induced $N K$ and $Y \delta T$ cells. Our results suggested that combination treatment with low-dose bortezomib and induced NK or y $\delta$ T cells had a synergistic cytotoxic effect on MM cells. This study provided a proof of principle for the design of future trials and investigation of this combination therapeutic strategy for MM treatment.
\end{abstract}

\section{INTRODUCTION}

Multiple myeloma (MM) is a hematological malignancy characterized by enhanced proliferation and accumulation of abnormal plasma cells [1,2]. Over the past two decades, novel agents like the proteasome inhibitor, bortezomib, and the immunomodulatory drug, lenalidomide, have improved clinical outcomes for patients with MM [3-5]. However, curative outcomes remain elusive because of high rates of disease relapse and development of drug resistance [6]. In addition, survival among those in whom lenalidomide and bortezomib fail is especially poor [7]. Therefore, novel and effective treatments are urgently needed. One potential therapeutic option involves the stimulation of the immune system to target and eliminate neoplastic cells.
Innate immune cells, including natural killer (NK) and $\gamma \delta \mathrm{T}$ cells, play important roles in anti-tumor immune surveillance $[8,9]$. Unlike antigen specific T cells, NK and $\gamma \delta \mathrm{T}$ cells do not require $\mathrm{MHC}$ or a specific tumor antigen for target recognition $[10,11]$. In clinical trials, immunotherapy using NK or $\gamma \delta \mathrm{T}$ cells has effectively treated various cancers $[9,12,13]$. Expanded and induced NK and $\gamma \delta \mathrm{T}$ cells exerted potent specific cytotoxicity against human MM cells in vitro [14-16] and the infusion of large numbers of induced NK cells was proven to be a feasible and safe method for MM treatment [17]. In addition, many drugs, such as carfilzomib, lenalidomide, and elotuzumab, enhanced NK cell cytotoxicity against myeloma [18-21]. All of these results suggested that treatment with induced NK and $\gamma \delta$ $\mathrm{T}$ cells along with chemotherapy drugs provides a promising treatment modality for the eradication of MM cells. 
NK and $\gamma \delta \mathrm{T}$ cell activity was regulated by the balance between the expression levels of numerous inhibitory and activating receptors [22, 23]. Modulation of the ligands to inhibitory and activating receptors on tumor cells represents a promising therapeutic approach that would sensitize cancer cells to $\gamma \delta \mathrm{T}$ and NK cells and increase cytotoxicity $[24,25]$. Interestingly, bortezomib has been shown to decrease the MM cell surface expression of HLA class I (a ligand for killer immunoglobulin-like receptors (KIR), which are inhibitory receptors), thereby sensitizing MM cells to lysis by NK cells isolated from peripheral blood (fresh NK cells) [24]. Our previous study indicated that induced NK cells had much lower KIR expression than did fresh NK cells [26]. Whether bortezomib sensitizes MM cells to lysis by in vitro induced NK and $\gamma \delta \mathrm{T}$ cells, and whether the clinical concentration of bortezomib directly affects the function of NK and $\gamma \delta$ $\mathrm{T}$ cells remain unknown.

Therefore, in this study, we analyzed the apoptotic effect of various concentrations of bortezomib on MM cells and induced NK and $\gamma \delta \mathrm{T}$ cells. Furthermore, we investigated whether bortezomib sensitized MM cells to lysis by induced NK and $\gamma \delta \mathrm{T}$ cells and the mechanism involved in this process. This information may eventually lead to the identification of the optimal dose and regimen for effective therapeutic treatment of MM using bortezomib in combination with immunotherapy using induced NK and $\gamma \delta$ T cells.

\section{RESULTS}

\section{Low-dose bortezomib did not suppress the viability and degranulation of induced NK and $\gamma \delta \mathrm{T}$ cells}

The percentage of fresh NK (NK cells in peripheral blood mononuclear cells (PBMCs) before induction) was $15.7 \%$ (11.2-20.6\%), whereas after 14 days of in vitro induction, the percentage of induced NK was $80.2 \%$ (67.9-95.6\%) (Figure 1A and 1C). Similarly, the percentage of fresh $\gamma \delta \mathrm{T}$ cells $(\gamma \delta \mathrm{T}$ cells in PBMCs before induction) was $1.2 \%(0.51-5.2 \%)$, whereas, after induction, the percentage of induced $\gamma \delta \mathrm{T}$ cells was $79.6 \%$ (60.7-93.3\%) (Figure 1B and 1D).

Bortezomib at a concentration of $20 \mathrm{nM}$ significantly reduced the percentage, viability, and degranulation of fresh NK and $\gamma \delta$ T cells (Figure S1). We also determined whether bortezomib treatment affected the functions of induced NK and $\gamma \delta \mathrm{T}$ cells. We found that $20 \mathrm{nM}$ bortezomib significantly induced apoptosis of induced NK and $\gamma \delta \mathrm{T}$ cells. However, $10 \mathrm{nM}$ (low-dose) bortezomib, a concentration higher than that which would be expected $48 \mathrm{~h}$ after a dose of intravenous bortezomib $\left(1.0 \mathrm{mg} / \mathrm{m}^{2}\right)$, did not suppress the viability of induced NK and $\gamma \delta$ T cells (Figure $1 \mathrm{E}$ and $1 \mathrm{~F}$ ). This supported the notion that the viability of adoptive transfer of in vitro induced NK and $\gamma \delta \mathrm{T}$ cells $48 \mathrm{~h}$ after an intravenous dose of bortezomib would not be inhibited by residual drug.

The expression of CD107a, which represents the killing capacity of immune cells, was determined to evaluate degranulation activity. Our results indicated that low-dose bortezomib did not inhibit the degranulation capacity of induced NK or $\gamma \delta$ T cells (Figure $1 \mathrm{G}$ and $1 \mathrm{H}$ ). This provided further evidence that residual drug in the blood did not suppress the killing capacity of in vitro induced NK and $\gamma \delta \mathrm{T}$ cells in bortezomib- treated patients.

\section{Bortezomib treatment increased the expression of MICA, MICB, Nectin-2, and PVR proteins on MM cells}

Bortezomib induced apoptosis in U266 and RPMI$8226 \mathrm{MM}$ cells in a dose-dependent manner (Figure S2). Evaluation of this may be accompanied by unspecific staining during the process of surface marker staining, therefore, we analyzed surface marker expression by gating on PI and annexin V double negative cells in order to exclude apoptotic cells.

To further investigate whether bortezomib increased the expression of NKG2D and DNAM-1 ligands in a dose dependent manner, MM cells were treated with varying concentrations of bortezomib. Bortezomib increased the expression of Nectin-2 and PVR on RPMI-8226 and U266 cells and the expression of MICA on RPMI8226 cells in a dose dependent manner. However, $5 \mathrm{nM}$ bortezomib caused the expression of MICA on U266 cells and MICB on RPMI-8226 and U266 cells to peak (Figure 2A). After incubation with $10 \mathrm{nM}$ bortezomib, the expression of MICA, Nectin-2, and PVR on both RPMI8226 and U266 cells and MICB on U266 cells reached a peak at $12 \mathrm{~h}$ (Figure 3B). In addition, the expression of MICB on RPMI-8226 cells consistently increased with time (Figure 2B). Increases in NKG2D and DNAM-1 ligand expression on $\mathrm{MM}$ cells were further confirmed by western blot (Figure 2C).

To further validate the expression of MICA, MICB, Nectin-2, and PVR, the mRNA levels of these genes were analyzed. Total RNA was isolated from RPMI-8226 and U266 cells incubated with $10 \mathrm{nM}$ bortezomib for $12 \mathrm{~h}$. Based on quantitative real-time reverse transcription PCR (qRT-PCR) analysis of the treated cells, levels of MICA, MICB, Nectin-2, and PVR mRNA were significantly greater in MM cells incubated with $10 \mathrm{nM}$ bortezomib compared to those in control MM cells ( $0 \mathrm{nM})$ (Figure 2D).

\section{Low-dose bortezomib sensitized MM cells to lysis by induced NK and $\gamma \delta$ T cells in vitro}

We have shown that low-dose bortezomib increased MICA, MICB, PVR, and Nectin-2 expression on MM cell lines. Because increased MICA, MICB, PVR, and Nectin-2 expression is associated with increased sensitivity of MM 
cells to NK and $\gamma \delta$ T cell-mediated lysis, we evaluated whether bortezomib treatment augmented the sensitivity of MM cells to induced NK and $\gamma \delta$ T cell-mediated cytolysis in vitro. Compared with untreated controls, exposure to bortezomib significantly enhanced the sensitivity of
MM cells to lysis by NK cells (Figure $3 \mathrm{~A}$ ) and $\gamma \delta$ T cells (Figure 3B) induced from the PBMCs of patients with MM. This supported the notion that the cytotoxicity of adoptively transferred induced NK and $\gamma \delta$ T cells to MM cells was enhanced by residual bortezomib in patients with MM.
A
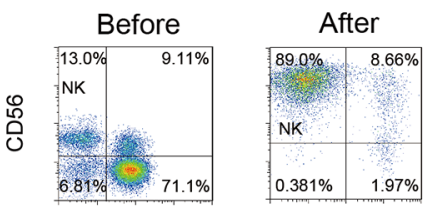

$\mathrm{CD} 3 \longrightarrow$

C

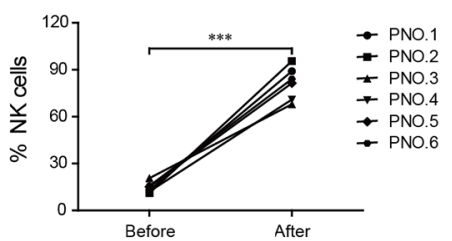

$\mathbf{E}$

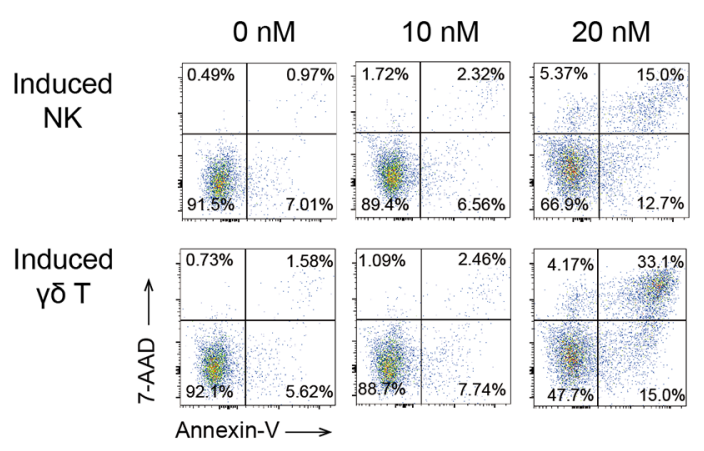

G

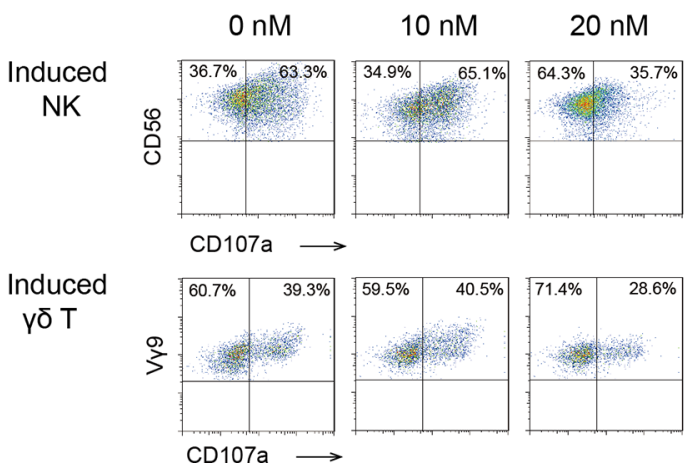

B

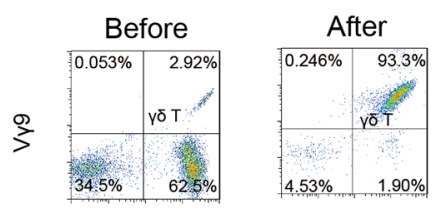

CD3 $\longrightarrow$

D

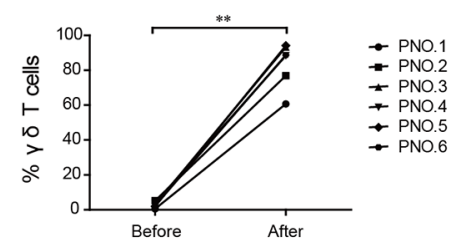

$\mathbf{F}$
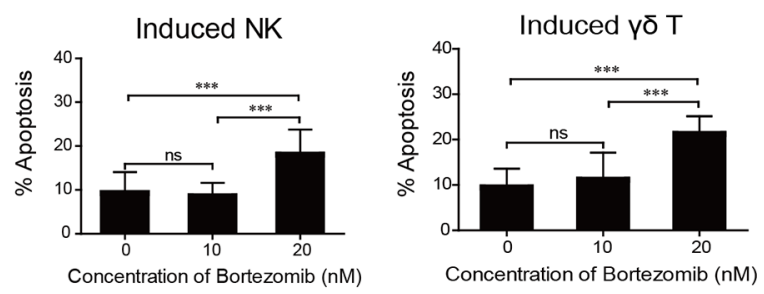

H

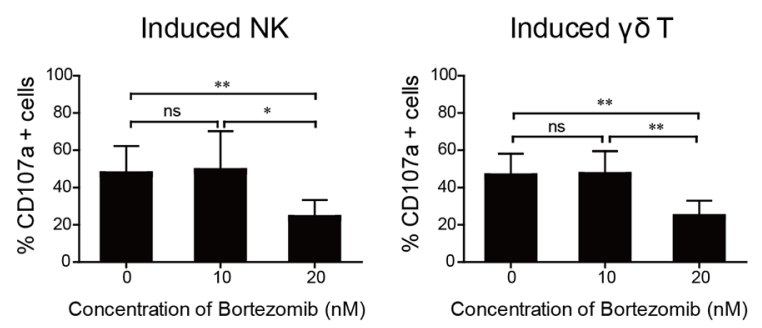

Figure 1: Effects of high- and low-dose bortezomib on the viability and degranulation of induced $\mathrm{NK}$ and $\gamma \delta \mathrm{T}$ cells. A representative FACS plot showing the percentage of NK (A) and $\gamma \delta \mathrm{T}$ cells $\mathbf{( B )}$ cells before and after 14 days of induction in patient number five. Graph showing the percentage of NK (C) and $\gamma \delta$ T cells (D) before and after 14 days of induction in six patients with MM. (E) Viability of induced NK and $\gamma \delta$ T cells after exposure to bortezomib. One representative experiment is shown. (F) Graph showing the apoptosis percentages of induced NK and $\gamma \delta \mathrm{T}$ cells exposed to increasing doses of bortezomib that were annexin $\mathrm{V}$ positive. (G) Representative FACS results show CD107a positive cells of induced NK and $\gamma \delta \mathrm{T}$ cells. (H) Comparison of the percentage of CD107a positive cells of induced NK and $\gamma \delta \mathrm{T}$ cells treated with increasing doses of bortezomib. ( ${ }^{*} p<0.05 ;{ }^{*} p<0.01 ; * * * p<0.001$; ns: not significant). 
A

RPMI-8226

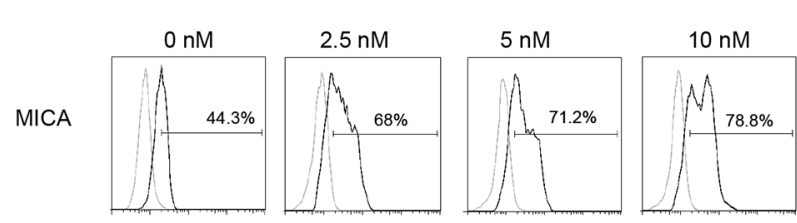

MICB
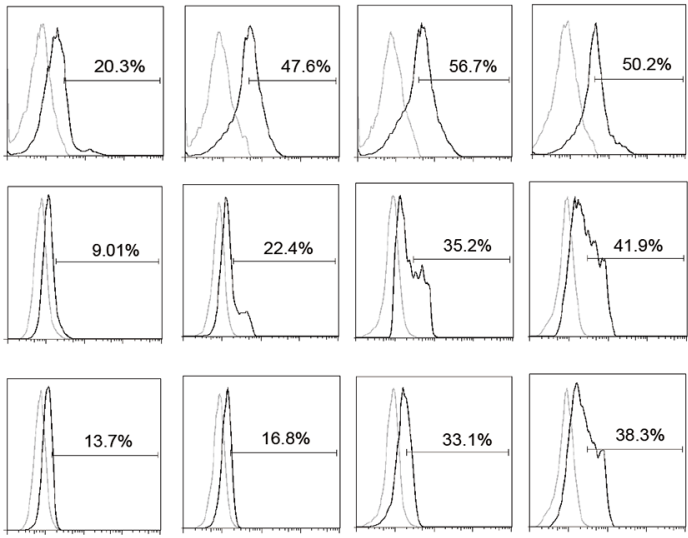

B

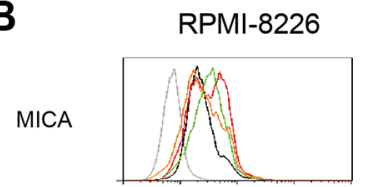

MICB
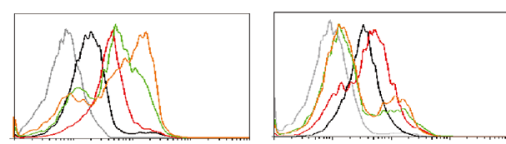

Nectin-2
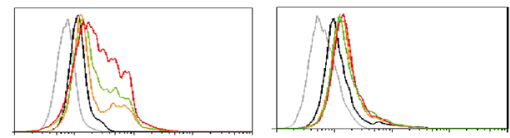

PVR
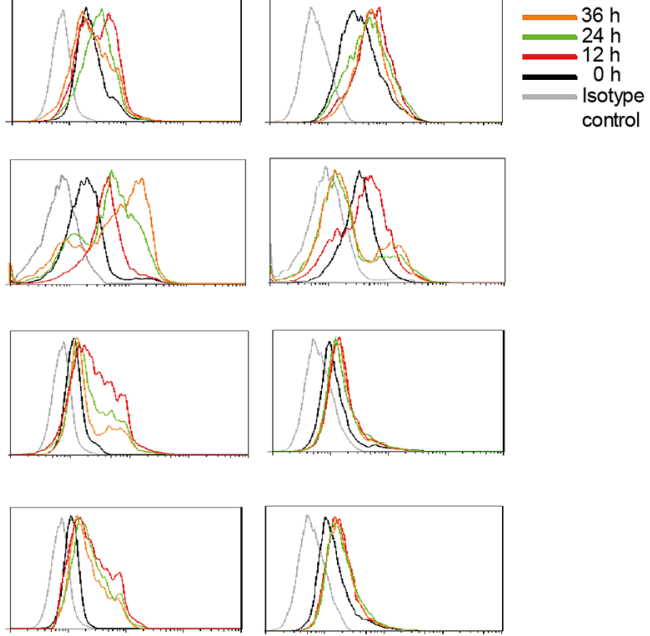

U266
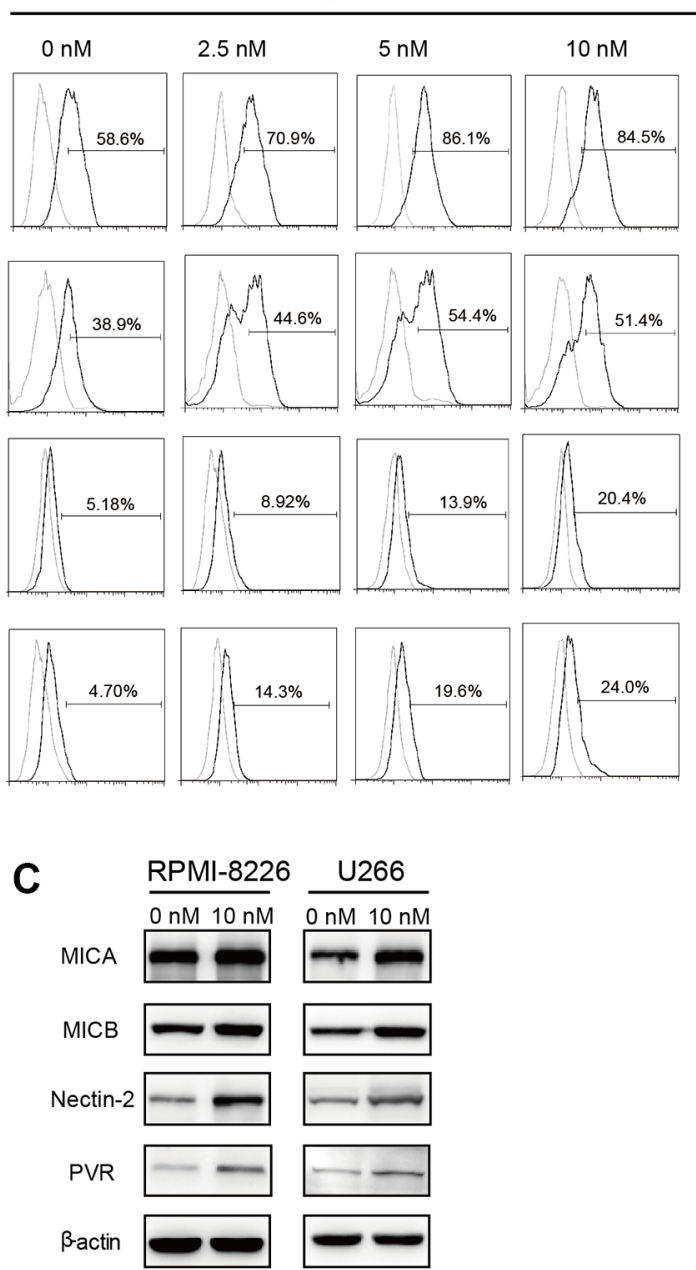

U266

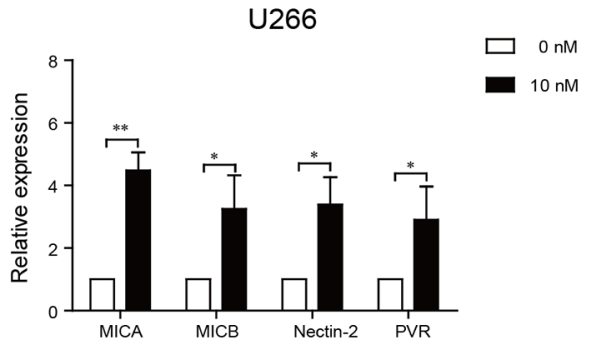

Figure 2: Bortezomib increased MICA, MICB, Nectin-2, and PVR expression on MM cells. Annexin V and 7-AAD double negative cells were gated and analyzed for surface marker expression. (A) Dose response: RPMI-8226 and U266 cells were exposed to increasing doses of bortezomib for $12 \mathrm{~h}$. (B) Time course: RPMI-8226 and U266 cells were incubated with low-dose (10 nM) bortezomib for increasing durations of time. (C) Representative western blot analysis of MICA, MICB, Nectin-2, and PVR expression in low-dose bortezomib-treated MM cells. $\beta$-actin was used as a loading control of cell lysates. (D) qRT-PCR analysis of MICA, MICB, Nectin-2, and PVR expression in RPMI-8226 and U266 cells exposed to low-dose bortezomib for $12 \mathrm{~h}$. Data are expressed as relative expression of MICA, MICB, Nectin-2, and PVR mRNA in low-dose bortezomib-treated MM cells over that of normal saline-treated control cells $\left({ }^{*} p<0.05 ; * * p<0.01 ; * * * p<0.001\right)$. 


\section{Induced $N K$ and $\gamma \delta \mathrm{T}$ cells displayed a higher level of NKG2D and DNAM-1 expression}

NKG2D and DNAM-1 are the receptors of MICA, MICB, Nectin-2, and PVR that are important for the cytotoxicity function of both NK and $\gamma \delta \mathrm{T}$ cells. We showed that low-dose bortezomib increased MICA, MICB, PVR, and Nectin-2 expression on MM cells as the target cells. We also evaluated whether effector cells expressed NKG2D and DNAM-1 and found that the expressions of NKG2D and DNAM- 1 on induced NK and $\gamma \delta$ T cells were significantly higher than those on fresh NK and fresh $\gamma \delta$ $\mathrm{T}$ cells (Figure 4). The data in Figure 4A, 4B, 4E, and 4F represent one representative patient and the data in Figure $4 \mathrm{C}, 4 \mathrm{D}, 4 \mathrm{G}$, and $4 \mathrm{H}$ represent all six patients. Overall, these results indicated that induced NK and $\gamma \delta \mathrm{T}$ cells were strongly activated immune cells that were more cytotoxic to MM cells when expressing NKG2D and DNAM-1 ligands.

\section{Low-dose bortezomib sensitized MM cells to lysis by induced NK and $\gamma \delta$ T cells through NKG2D and DNAM-1 ligands}

We observed that there was a higher level of MICA, MICB, PVR, and Nectin-2 expression on bortezomibincubated MM cells than on unincubated MM cells, and a high level of NKG2D and DNAM-1 expression on induced NK and $\gamma \delta$ T cells. We next evaluated whether this amount of NKG2D and DNAM-1 ligand upregulation was relevant to the increased sensitivity of MM cells to induced NK and $\gamma \delta \mathrm{T}$ cell-mediated lysis. Induced NK and $\gamma \delta \mathrm{T}$ cells were incubated with NKG2D or DNAM-1 blocking antibody before cytotoxicity assays were performed with low-dose bortezomib-treated MM cells. We observed that NKG2D and DNAM-1 blocking antibodies considerably reduced NK and $\gamma \delta$ T cell cytotoxicity to low-dose bortezomibtreated MM cells, whereas a control monoclonal antibody $(\mathrm{mAb})$ did not decrease the cytotoxicity. This indicated that the increased cytotoxicity of induced NK and $\gamma \delta$ T cells was dependent on NKG2D and DNAM-1 activation. Moreover, it appeared that the cytotoxicity of induced NK and $\gamma \delta \mathrm{T}$ cells against low-dose bortezomib-treated MM cells was more dependent on NKG2D recognition than DNAM-1 because anti-NKG2D mAbs more substantially reduced the cytotoxicity (Figure 5A and 5B).

\section{DISCUSSION}

Recent efforts to combine conventional therapy with immunotherapy for $\mathrm{MM}$ have resulted in the development of several promising therapies. However, questions about how to combine and sequence different therapies for the treatment of MM remain unanswered. In this study, we found that high dose $(20 \mathrm{nM})$ bortezomib induced the apoptosis of induced NK and $\gamma \delta \mathrm{T}$ cells and thereby inhibited NK and $\gamma \delta \mathrm{T}$ cell-mediated cytotoxicity, whereas low-dose $(10 \mathrm{nM})$ bortezomib enhanced MM cell sensitivity to induced NK and $\gamma \delta \mathrm{T}$ cell-mediated lysis and supported NK and $\gamma \delta$ T cell-based immunotherapy.
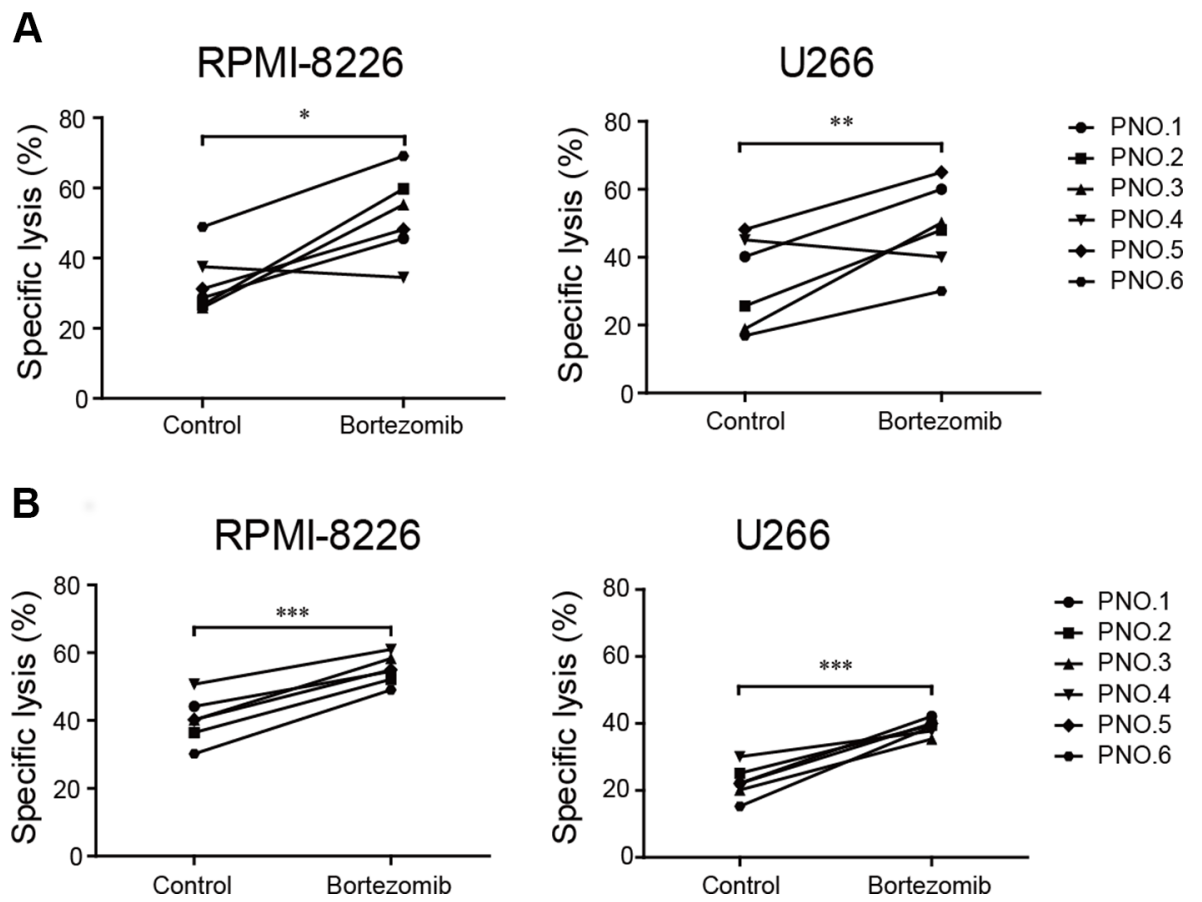

Figure 3: Low-dose bortezomib treatment enhanced the sensitivity of MM cells to induced NK and $\gamma \delta$ T cell-mediated lysis. (A) The cytotoxicity of induced NK cells to low-dose bortezomib-treated and untreated (control) MM cells. (B) The cytotoxicity of induced $\gamma \delta$ T cells to low-dose bortezomib-treated and untreated (control) MM cells. $(* p<0.05 ; * * p<0.01 ; * * *<0.001)$. 
Therefore, the optimal clinical dose and regimen for bortezomib administration must be established. Typically, bortezomib is administered twice weekly for two weeks, with a minimum of $72 \mathrm{~h}$ between doses, to allow for the restoration of proteasome function in normal cells. Each cycle of four doses (i.e., administration on days $1,4,8$, and 11) is followed by a 10-day rest [27]. A pharmacokinetic study indicated that $24-48 \mathrm{~h}$ after the day 11 dose, the concentration of bortezomib in the blood was approximately $10 \mathrm{nM}$ [28]. Similarly, we confirmed that $10 \mathrm{nM}$ bortezomib increased the expression of NKG2D and DNAM-1 ligands on MM cells and had little effect on the viability of fresh (Figure S1) and induced NK and $\gamma \delta$ $\mathrm{T}$ cells in vitro. In contrast, concentrations of bortezomib immediately following infusion were high enough to not only eliminate MM cells, but also have unfavorable effects on immunocytes. Therefore, an infusion of expanded and activated immunocytes to patients within the time period when the residual MM cells remain sensitized to NK or $\gamma \delta \mathrm{T}$ cells and the concentration of bortezomib has fewer unfavorable effects on immunocytes may represent an effective cellular immunotherapy regimen. The blood of patients can be drawn one or two days before treatment, then it would take about two weeks ex vivo to induce and expand sufficient numbers of immunocytes for infusion. As a result, adaptive infusion of induced NK and $\gamma \delta$ $T$ cells may increase the therapeutic effects of conventional bortezomib therapy.

Over the last decade, we have witnessed a growing interest in the anti-tumor function of innate immune cells,
A

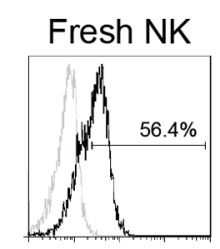

NKG2D $\longrightarrow$

C

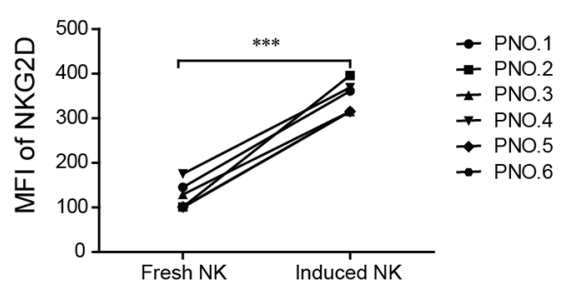

E

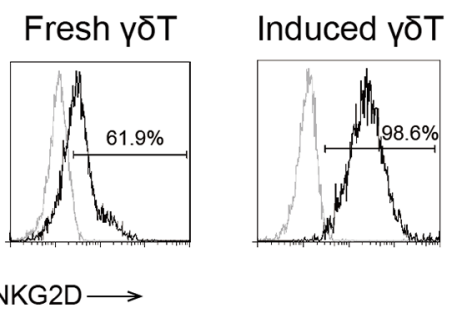

G

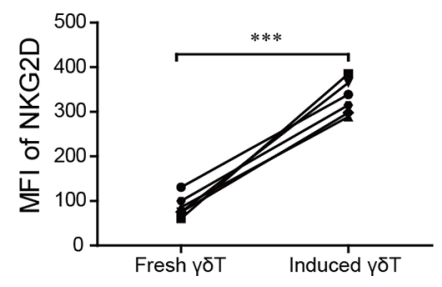

B

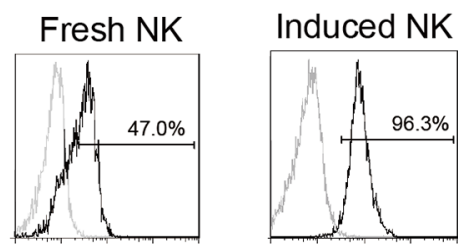

DNAM-1 $\longrightarrow$

D

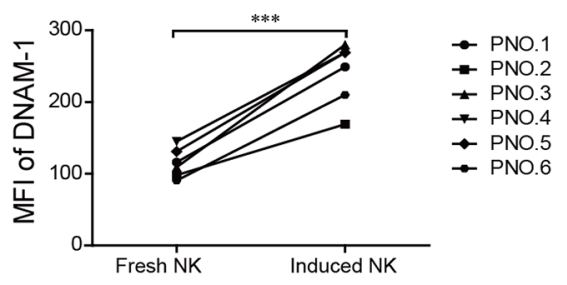

F

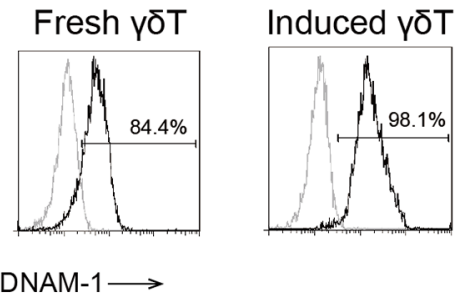

H

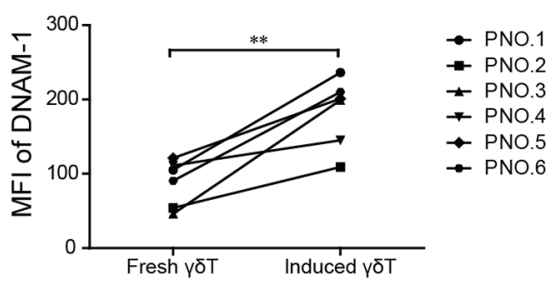

Figure 4: NKG2D and DNAM-1 expression in induced and fresh NK and $\boldsymbol{\gamma} \boldsymbol{T}$ T cells. The percentage of NKG2D (A) and DNAM-1 (B) on fresh and induced NK cells in patient number five. The mean fluorescence index (MFI) of NKG2D (C) and DNAM-1 (D) on induced and fresh NK cells in six patients with MM. The percentage of NKG2D (E) and DNAM-1 (F) on fresh and induced $\gamma \delta$ $\mathrm{T}$ cells in patient number five. The MFI of NKG2D $(\mathbf{G})$ and DNAM-1 $(\mathbf{H})$ on induced and fresh $\gamma \delta$ T cells in six patients with MM. $(* * p<0.01 ; * * *<0.001)$. 
such as NK and $\gamma \delta \mathrm{T}$ cells, that have shown therapeutic potential in patients with MM $[15,17]$. Furthermore, $\gamma \delta$ $\mathrm{T}$ cells and NK cells seem to have synergistic effects. The $\gamma \delta$ T cells induce robust NK cell-mediated antitumor cytotoxicity [29] and NK cells maintain the homeostasis of $\gamma \delta \mathrm{T}$ cells [30]. In addition, $\gamma \delta \mathrm{T}$ cells have been shown to kill NK-resistant tumor cells, indicating a potential for synergistic therapeutic effects. Nevertheless, patients with MM have fewer or less active NK and $\gamma \delta$ T cells [31-33]. In our study, we successfully expanded NK and $\gamma \delta$ T cells from patients with $\mathrm{MM}$ and found no difference in the expansion fold of $\mathrm{NK}$ and $\gamma \delta \mathrm{T}$ cells between patients with MM and normal healthy controls (Figure S3). Induced NK and $\gamma \delta \mathrm{T}$ cells are strongly activated immune cells that have a greater expression of CD69 than fresh NK and $\gamma \delta \mathrm{T}$ cells, as indicated by our previous study [26]. Therefore, treatment with adoptively transferred, in vitro expanded and induced NK and $\gamma \delta$ T cells might be a prospective therapeutic method for patients with MM.

Despite the link between malignant transformation and expression of danger signals, tumor cells are often insufficiently recognized by NK and $\gamma \delta$ T cells. This may limit the ability of both endogenous and adoptively infused autologous NK and $\gamma \delta$ T cells to induce antitumor effects. Therefore, increasing the surface density of stimulatory ligands represents an attractive approach to elicit or enhance NK or $\gamma \delta$ T cell-based antitumor responses. The anti-cancer properties of bortezomib are complex and are mediated in part by interfering with host immunity [34]. In our study, we observed that bortezomib not only induced the apoptosis of MM cells, but also enhanced the expression of activating ligands, including MICA, MICB, PVR, and Nectin-2. Bortezomib also increased Fas and TRAIL ligand expression (Figure S4), thereby enhancing the cytotoxic function of immune cells $[35,36]$. Therefore, bortezomib activated immune responses through multiple mechanisms. However, low-dose bortezomib enhanced NK and $\gamma \delta$ T cell-mediated lysis of MM cells primarily by upregulating the expression of NKG2D and DNAM-1 ligands on MM cells.

In conclusion, treatment with the combination of low-dose bortezomib and induced NK or $\gamma \delta$ T cells had a synergistic cytotoxic effect on MM cells. The mechanism underlying the enhanced tumor cell killing may involve
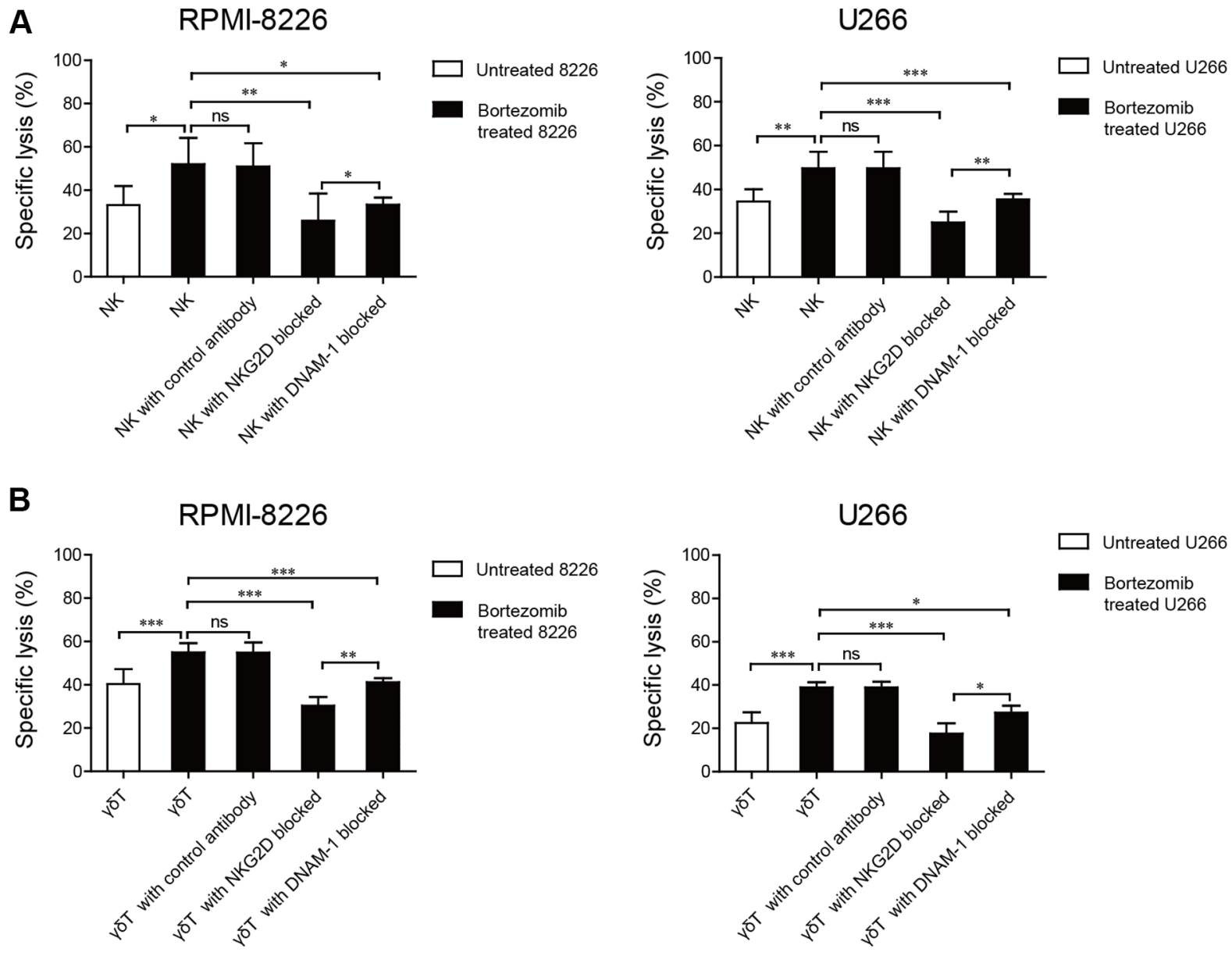

Figure 5: Enhanced NK and $\gamma \delta$ T cell cytotoxicity against low-dose bortezomib-treated MM cells correlated with the interactions between NKG2D and DNAM-1 receptors and their ligands. Increased NK cell and $\gamma \delta \mathrm{T}$ cell killing was abolished by blocking NKG2D or DNAM-1 on NK cells (A) and $\gamma \delta$ T cells $(\mathbf{B}) .\left({ }^{*} p<0.05 ; * * p<0.01 ; * * p<0.001\right.$; ns: not significant). 
the increased expression of MICA, MICB, PVR, and Nectin-2 proteins on MM cells and the ligands of the activating receptors, NKG2D and DNAM-1. The results of this study provided a proof of principle for the design of future trials and investigation of this combination therapeutic strategy in clinical settings.

\section{MATERIALS AND METHODS}

\section{Patient enrollment}

Six patients newly diagnosed with MM were enrolled in this study, all of whom provided written informed consent for the use of the biospecimens for research purposes. The study was carried out in accordance with the approved guidelines "Use of experimental animals and human subjects". The study was approved by the Ethics Committee of the First Hospital of Jilin University. Patient information is shown in Table 1.

\section{Pharmacological agents}

Bortezomib was purchased from Xian Janssen Pharmaceutical Ltd. (Xi'an, China) and dissolved in normal saline to a concentration of $100 \mathrm{nM}$.

\section{Cell culture}

The MM cell lines, U266 and RPMI-8226, were kindly provided by Dr. Jifan Hu at Stanford University Medical School, Palo Alto Veterans Institute for Research, Palo Alto, CA, USA. Both cell lines were cultured in RPMI-1640 medium (Gibco, Grand Island, NY, USA) supplemented with 10\% heat-inactivated FBS (Gibco), $100 \mathrm{U} / \mathrm{mL}$ penicillin, and $100 \mathrm{mg} / \mathrm{mL}$ streptomycin (Gibco) at $37^{\circ} \mathrm{C}$ in a humidified $5 \% \mathrm{CO}_{2}$ incubator.

\section{Expansion and isolation of induced NK and $\gamma \delta \mathrm{T}$ cells}

Heparinized peripheral blood samples were obtained from the six patients with MM. Blood samples were centrifuged at $1800 \times \mathrm{g}$ for $10 \mathrm{~min}$ and plasma was transferred to new tubes. PBMCs were isolated by density gradient centrifugation using Ficoll medium (Axis-Shield PoC AS, Oslo, Norway) at $800 \times \mathrm{g}$ for $30 \mathrm{~min}$. To obtain induced NK cells, PBMCs at a density of $1 \times 10^{6}$ cells $/ \mathrm{mL}$ were cultured in AlyS 505 NK-EX (CSTI, Sendai-shi, Miyagi, Japan) containing 5\% auto-plasma, $500 \mathrm{U} / \mathrm{mL}$ interleukin (IL)-2 (Miltenyi Biotec, Bergisch Gladbach, Germany), and $10 \mathrm{ng} / \mathrm{mL}$ anti-CD3 mAbs (Miltenyi Biotec). To amplify $\gamma \delta$ T cells, PBMCs were cultured in complete medium with $1 \mu \mathrm{M}$ zoledronate (zoledronic acid, Jilin Province Xidian Pharmaceutical Sci-Tech Development Co., Jilin, China) and 400 U/mL IL-2. Fresh complete medium supplemented with IL-2 $(500 \mathrm{U} / \mathrm{mL})$ was added every two or three days. Purified induced CD3$\mathrm{CD} 56+\mathrm{NK}$ cells and CD3+V $\gamma 9+\gamma \delta \mathrm{T}$ cells were isolated using a flexible BD Influx ${ }^{\mathrm{TM}}$ cell sorter (BD Biosciences, San Jose, CA, USA).

\section{In vitro treatment and flow cytometry}

MM cells were incubated with $0,5,10$, and $20 \mathrm{nM}$ bortezomib for $12 \mathrm{~h}$ and $\mathrm{MM}$ cells were incubated with $10 \mathrm{nM}$ bortezomib for 12, 24, and $36 \mathrm{~h}$. Cells were then stained with Nectin-2-PE (BD Biosciences), PVR-PE, MICA-PE, and MICB-APC (R\&D Systems, Minneapolis, MN, USA). Purified induced NK and $\gamma \delta$ T cells were stained with CD56-FITC (BD Biosciences) or V $\gamma 9$ FITC, CD3-PerCp (BD Biosciences), NKG2D-APC (BD Biosciences), and DNAM-1-PE (BD Biosciences). Appropriate isotype-matched antibodies were used as controls. Data were analyzed using a BD FACSCalibur (BD Biosciences) with Cell Quest Pro software and final analysis was performed using FlowJo software (Tree Star Inc., Ashland, OR, USA).

\section{Detection of apoptosis}

MM cells were incubated with $0,5,10$, and $20 \mathrm{nM}$ bortezomib for $12 \mathrm{~h}$. In addition, induced NK and $\gamma \delta$ $\mathrm{T}$ cells were treated with 0,10 , and $20 \mathrm{nM}$ bortezomib for $12 \mathrm{~h}$. The proportions of living, dead, and apoptotic cells were determined using an annexin $\mathrm{V}$ and 7-AAD staining kit (eBioscience, San Diego, CA, USA) according to the manufacturer's protocol. Quantitative analysis was performed using flow cytometry.

\section{Degranulation assay}

A CD107a translocation assay was used to evaluate the degranulation activity of the fresh and induced NK and $\gamma \delta \mathrm{T}$ cells as previously described [37]. Purified induced NK and $\gamma \delta$ T cells from patients with MM were incubated with 0,10 , and $20 \mathrm{nM}$ bortezomib for $12 \mathrm{~h}$. The drugtreated cells were mixed with RPMI-8226 cells at a ratio of $10: 1$ and incubated at $37^{\circ} \mathrm{C}$ in $5 \% \mathrm{CO}_{2}$. After $4 \mathrm{~h}$ of incubation, the cells were collected and stained with CD56FITC or V $\gamma 9$-FITC, CD3-PerCp, and CD107a-APC (BD Biosciences). After staining, the cells were analyzed using a BD FACSCalibur flow cytometer (BD Biosciences).

\section{Quantitative real-time reverse transcription PCR (qRT-PCR)}

Total RNA was extracted from MM cells treated with $10 \mathrm{nM}$ bortezomib using a Promega SV Total RNA Isolation System (Promega Corporation, Madison, WI, USA), according to the manufacturer's instructions. After removing genomic DNA contamination with DNase I (Sigma, St. Louis, MO, USA), M-MLV reverse 
Table 1: Patient clinical characteristics

\begin{tabular}{ccccc}
\hline Patients No. & Gender & Age & Type of Tumor & Stages of Disease \\
\hline 1 & Male & 68 & MM & ISS III/DS IIIA \\
2 & Female & 59 & MM & ISS I/DS IIA \\
3 & Male & 59 & MM & ISS I/DS IIIB \\
4 & Male & 46 & MM & ISS I/DS IIA \\
5 & Male & 57 & MM & ISS III/DS IIA \\
6 & Female & 64 & MM & ISS III/DS IIIA \\
\hline
\end{tabular}

transcriptase (Invitrogen, Carlsbad, CA, USA) was used to synthesize cDNA. MICA, MICB, Nectin-2, and PVR mRNA expression was quantified by qRT-PCR using a CFX384 ${ }^{\mathrm{TM}}$ Real Time system (Bio-Rad, Hercules, CA, USA). The PCR reactions were set up in a final volume of $10 \mu \mathrm{L}$ with $5 \mu \mathrm{L}$ SYBR Green qPCR Mix (Roche, Indianapolis, IN, USA) and 10 pmol of each sense and antisense primer. Primer sequences were as follows: for human MICA gene, sense: 5'-GTTTCTGCTGTTGCTGCT GCTGC-3' and anti-sense: 5'-ATCCCTGTGGTCACTC GTCC-3'; for human MICB gene, sense: 5'-ATGTTTCT GCTGCTATGCCATG- $3^{\prime}$ and anti-sense: $5^{\prime}$-GACCCTCT GCCGCTGATGT-3'; for human PVR gene, sense: 5'-TGA GGATGTTCGGGTTGCG-3' and anti-sense: 5'-CTGGCT CGTATTGGGCATC-3'; for human Nectin-2 gene, sense: 5'-ACCTGCGAACCACCAGAATG-3' and anti-sense: 5'-CTTGCCCAGTGCTCTGCTT-3'. The mRNA of human $\beta$-actin was also quantified and used as an internal standard. Primers for $\beta$-actin were as follows: sense: $5^{\prime}$-AAGATC ATTGCTCCTCCTG-3' and antisense: 5'-CGTCATACTC CTGCTTGCTG-3'. The PCR amplification procedure was as follows: $10 \mathrm{~s}$ at $95^{\circ} \mathrm{C}$ followed by 40 cycles of $5 \mathrm{~s}$ at $95^{\circ} \mathrm{C}$ and $30 \mathrm{~s}$ at $64^{\circ} \mathrm{C}$. Each standard and sample value was determined in triplicate in three independent experiments. In each experiment, expression of MICA, MICB, Nectin-2, and PVR under each experimental condition was calculated using threshold cycle $(\mathrm{Ct})$ values standardized to $\beta$-actin (housekeeping gene), applying the 2-( $\Delta \mathrm{Ct})$ method [38].

\section{Western blot analysis}

Protein samples from MM cells treated with $10 \mathrm{nM}$ bortezomib were homogenized using radioimmunoprecipitation assay (RIPA) lysis buffer. Equal amounts of protein were separated from each sample using SDS-PAGE and transferred onto polyvinylidene fluoride (PVDF) membranes. The membranes were then incubated for $1 \mathrm{~h}$ with blocking buffer containing $5 \%$ skimmed milk and incubated with the primary antibodies for MICA, MICB, Nectin-2, and PVR along with rabbit anti-goat or goat anti-mouse IgG antibody (R\&D Systems). An Enhanced Chemiluminescence (ECL) Detection System was used to visualize the proteins.

\section{Cytotoxicity assay}

A calcein-acetoxymethyl (AM) release assay was used as previously described to assess cytotoxicity [39]. The target MM cells were pretreated with lowdose $(10 \mathrm{nM})$ bortezomib for $12 \mathrm{~h}$, labeled with $3.5 \mu \mathrm{M}$ of calcein-AM, and incubated in a humidified incubator at $37^{\circ} \mathrm{C}$ with $5 \% \mathrm{CO}_{2}$ for $30 \mathrm{~min}$. After washing twice with PBS, target cells were adjusted to a concentration of $5 \times 10^{4}$ cells $/ \mathrm{mL}$ with $5 \%$ FBS RPMI-1640 medium and seeded into 96-well plates. As to the experimental group, the induced NK and $\gamma \delta \mathrm{T}$ effector cells $(100 \mu \mathrm{L})$, treated and untreated with antibodies to NKG2D or DNAM-1 (R\&D Systems), were added to the target cells at a ratio of $10: 1$ and incubated at $37^{\circ} \mathrm{C}$ for $4 \mathrm{~h}$. During the assay, spontaneous release controls were set by incubating target cells with low-dose bortezomib in medium alone and maximum release controls were set when target cells were treated with $1 \%$ Triton X-100. After incubation, the supernatant was harvested and transferred to a new plate. Fluorescence at $485 \mathrm{~nm}$ of excitation light wavelength and $528 \mathrm{~nm}$ of emission wavelength was assessed using a BioTek Synergy HT Microplate Reader (BioTek Instruments, Winooski, VT, USA). Specific lysis was calculated according to the following formula: [(experimental release - spontaneous release) / (maximum release - spontaneous release) $] \times 100 \%$. All experiments were performed in triplicate and at least three independent experiments were completed.

\section{Statistical analysis}

Data were analyzed using non-parametric tests (Wilcoxon's signed rank test, Wilcoxon's sum-rank test) using SPSS 19.0 software (SPSS Inc., Chicago, IL, USA). The comparative $C$ T method was applied for the qRT-PCR assay according to the delta-delta $C$ T method [40]. Results were indicated as mean $\pm \mathrm{SD}$ and considered significant at a $p<0.05$.

\section{ACKNOWLEDGMENTS}

We would like to thank Editage [www.editage.cn] for English language editing. 


\section{CONFLICTS OF INTEREST}

The authors declare no competing financial interest.

\section{GRANT SUPPORT}

This work was supported in part by grants from National Natural Science Foundation of China (31470798, 81402436), Provincial Science Fund of Jilin Province Development and Reform Commission (2014N147), Provincial Science Fund of Jilin Provincial Department of Finance (20140414014GH, 20150204027YY and 20150520155JH), Norman Bethune Program of Jilin University (2012202), and Youth Fund of the First Hospital of Jilin University (JDYY72016003).

\section{Authors'contributions}

J.C., W.L., Y.Z., S.Z. and H.J. conceived and designed the research. C.N., M.L., F.J., S.H., L-J. Z., and L.Z. performed the experiments and analyzed the data. J.X. and D.X. contributed to sample collection. C.N. and S.Z. wrote the paper. All authors reviewed the manuscript.

\section{REFERENCES}

1. Fuchs O. Targeting of NF-kappaB signaling pathway, other signaling pathways and epigenetics in therapy of multiple myeloma. Cardiovasc Hematol Disord Drug Targets. 2013; 13:16-34.

2. Anderson KC. Bortezomib therapy for myeloma. Curr Hematol Rep. 2004; 3:65.

3. Hallett WH, Ames E, Motarjemi M, Barao I, Shanker A, Tamang DL, Sayers TJ, Hudig D, Murphy WJ. Sensitization of tumor cells to NK cell-mediated killing by proteasome inhibition. J Immunol. 2008; 180:163-170.

4. Rollig C, Knop S, Bornhauser M. Multiple myeloma. Lancet. 2015; 385:2197-2208.

5. Moreau P, Attal M, Facon T. Frontline therapy of multiple myeloma. Blood. 2015; 125:3076-3084.

6. Kumar SK, Lee JH, Lahuerta JJ, Morgan G, Richardson PG, Crowley J, Haessler J, Feather J, Hoering A, Moreau P, LeLeu X, Hulin C, Klein SK, et al. Risk of progression and survival in multiple myeloma relapsing after therapy with IMiDs and bortezomib: a multicenter international myeloma working group study. Leukemia. 2012; 26:149-157.

7. Zou Y, Ma X, Yu H, Hu C, Fan L, Ran X. Carfilzomib/ pomalidomide single-agent or in combination with other agents for the management of relapsed/refractory multiple myeloma : a meta-analysis of 37 trials. Oncotarget. 2016 Jul 21. doi: 10.18632/oncotarget.10768. [Epub ahead of print].

8. Campbell KS, Hasegawa J. Natural killer cell biology: an update and future directions. The Journal of allergy and clinical immunology. 2013; 132:536-544.
9. Meraviglia S, Lo Presti E, Dieli F, Stassi G. gammadelta $\mathrm{T}$ cell-based anticancer immunotherapy: progress and possibilities. Immunotherapy. 2015; 7:949-951.

10. Guo Y, Feng X, Jiang Y, Shi X, Xing X, Liu X, Li N, Fadeel B, Zheng C. PD1 blockade enhances cytotoxicity of in vitro expanded natural killer cells towards myeloma cells. Oncotarget. 2016; 7:48360-48374. doi: 10.18632/ oncotarget.10235.

11. Kabelitz D. Human gammadelta T cells: From a neglected lymphocyte population to cellular immunotherapy: A personal reflection of 30years of gammadelta $\mathrm{T}$ cell research. Clin Immunol. 2016.

12. Rezvani K, Rouce RH. The Application of Natural Killer Cell Immunotherapy for the Treatment of Cancer. Frontiers in immunology. 2015; 6:578.

13. Fisher JP, Heuijerjans J, Yan M, Gustafsson K, Anderson J. gammadelta $\mathrm{T}$ cells for cancer immunotherapy: A systematic review of clinical trials. Oncoimmunology. 2014; 3:e27572.

14. Burjanadze M, Condomines M, Reme T, Quittet P, Latry P, Lugagne C, Romagne F, Morel Y, Rossi JF, Klein B, Lu ZY. In vitro expansion of gamma delta T cells with antimyeloma cell activity by Phosphostim and IL-2 in patients with multiple myeloma. Br J Haematol. 2007; 139:206-216.

15. Knight A, Mackinnon S, Lowdell MW. Human Vdelta1 gamma-delta $\mathrm{T}$ cells exert potent specific cytotoxicity against primary multiple myeloma cells. Cytotherapy. 2012; 14:1110-1118.

16. Garg TK, Szmania SM, Khan JA, Hoering A, Malbrough PA, Moreno-Bost A, Greenway AD, Lingo JD, Li X, Yaccoby S, Suva LJ, Storrie B, Tricot G, et al. Highly activated and expanded natural killer cells for multiple myeloma immunotherapy. Haematologica. 2012; 97:1348-1356.

17. Szmania S, Lapteva N, Garg T, Greenway A, Lingo J, Nair B, Stone K, Woods E, Khan J, Stivers J, Panozzo S, Campana D, Bellamy WT, et al. Ex vivo-expanded natural killer cells demonstrate robust proliferation in vivo in high-risk relapsed multiple myeloma patients. Journal of immunotherapy. 2015; 38:24-36.

18. Collins SM, Bakan CE, Swartzel GD, Hofmeister CC, Efebera YA, Kwon H, Starling GC, Ciarlariello D, Bhaskar S, Briercheck EL, Hughes T, Yu J, Rice A, et al. Elotuzumab directly enhances NK cell cytotoxicity against myeloma via CS1 ligation: evidence for augmented NK cell function complementing ADCC. Cancer Immunol Immunother. 2013; 62:1841-1849.

19. Balasa B, Yun R, Belmar NA, Fox M, Chao DT, Robbins MD, Starling GC, Rice AG. Elotuzumab enhances natural killer cell activation and myeloma cell killing through interleukin-2 and TNF-alpha pathways. Cancer Immunol Immunother. 2015; 64:61-73.

20. Lagrue K, Carisey A, Morgan DJ, Chopra R, Davis DM. Lenalidomide augments actin remodeling and lowers NKcell activation thresholds. Blood. 2015; 126:50-60.

21. Yang G, Gao M, Zhang Y, Kong Y, Gao L, Tao Y, Han Y, Wu H, Meng X, Xu H, Zhan F, Wu X, Shi J. 
Carfilzomib enhances natural killer cell-mediated lysis of myeloma linked with decreasing expression of HLA class I. Oncotarget. 2015; 6:26982-26994. doi: 10.18632/ oncotarget. 4831 .

22. Bryceson YT, Chiang SC, Darmanin S, Fauriat C, Schlums H, Theorell J, Wood SM. Molecular mechanisms of natural killer cell activation. Journal of innate immunity. 2011; 3:216-226.

23. Van Acker HH, Anguille S, Van Tendeloo VF, Lion E. Empowering gamma delta $\mathrm{T}$ cells with antitumor immunity by dendritic cell-based immunotherapy. Oncoimmunology. 2015; 4:e1021538.

24. Shi J, Tricot GJ, Garg TK, Malaviarachchi PA, Szmania SM, Kellum RE, Storrie B, Mulder A, Shaughnessy JD, Jr., Barlogie B, van Rhee F. Bortezomib down-regulates the cell-surface expression of HLA class I and enhances natural killer cell-mediated lysis of myeloma. Blood. 2008; 111:1309-1317.

25. Kim HS. A multifaceted approach targeting NK cells for better treatment of cancer: focus on hematological malignancies. Blood research. 2015; 50:189-191.

26. Niu C, Jin H, Li M, Xu J, Xu D, Hu J, He H, Li W, Cui J. In vitro analysis of the proliferative capacity and cytotoxic effects of ex vivo induced natural killer cells, cytokineinduced killer cells, and gamma-delta $\mathrm{T}$ cells. BMC Immunol. 2015; 16:61.

27. Schwartz R, Davidson T. Pharmacology, pharmacokinetics, and practical applications of bortezomib. Oncology. 2004; 18:14-21.

28. Moreau P, Karamanesht, II, Domnikova N, Kyselyova MY, Vilchevska KV, Doronin VA, Schmidt A, Hulin C, Leleu X, Esseltine DL, Venkatakrishnan K, Skee D, et al. Pharmacokinetic, pharmacodynamic and covariate analysis of subcutaneous versus intravenous administration of bortezomib in patients with relapsed multiple myeloma. Clinical pharmacokinetics. 2012; 51:823-829.

29. Maniar A, Zhang X, Lin W, Gastman BR, Pauza CD, Strome SE, Chapoval AI. Human gammadelta T lymphocytes induce robust NK cell-mediated antitumor cytotoxicity through CD137 engagement. Blood. 2010; 116:1726-1733.

30. Braza MS, Klein B. Anti-tumour immunotherapy with Vgamma9Vdelta2 T lymphocytes: from the bench to the bedside. Br J Haematol. 2013; 160:123-132.

31. Han W, Zhang X, Jia Z, He J, Chao H, Yang J, Xiao R, Lu X. Study of NK cells dysfunction in multiple myeloma patients. Zhonghua Xue Ye Xue Za Zhi. 2015; 36:922-925.
32. Castella B, Foglietta M, Sciancalepore P, Rigoni M, Coscia M, Griggio V, Vitale C, Ferracini R, Saraci E, Omede P, Riganti C, Palumbo A, Boccadoro M, et al. Anergic bone marrow Vgamma9Vdelta2 T cells as early and long-lasting markers of PD-1-targetable microenvironmentinduced immune suppression in human myeloma. Oncoimmunology. 2015; 4:e1047580.

33. Ponzetta A, Benigni G, Antonangeli F, Sciume G, Sanseviero E, Zingoni A, Ricciardi MR, Petrucci MT, Santoni A, Bernardini G. Multiple Myeloma Impairs Bone Marrow Localization of Effector Natural Killer Cells by Altering the Chemokine Microenvironment. Cancer Res. 2015; 75:4766-4777.

34. Pellom ST, Jr., Dudimah DF, Thounaojam MC, Sayers TJ, Shanker A. Modulatory effects of bortezomib on host immune cell functions. Immunotherapy. 2015; 7:1011-1022.

35. Shanker A, Pellom ST, Jr., Dudimah DF, Thounaojam MC, de Kluyver RL, Brooks AD, Yagita H, McVicar DW, Murphy WJ, Longo DL, Sayers TJ. Bortezomib Improves Adoptive T-cell Therapy by Sensitizing Cancer Cells to FasL Cytotoxicity. Cancer Res. 2015; 75:5260-5272.

36. Seki N, Toh U, Sayers TJ, Fujii T, Miyagi M, Akagi Y, Kusukawa J, Kage M, Shirouzu K, Yamana H. Bortezomib sensitizes human esophageal squamous cell carcinoma cells to TRAIL-mediated apoptosis via activation of both extrinsic and intrinsic apoptosis pathways. Mol Cancer Ther. 2010; 9:1842-1851.

37. Bryceson YT, Rudd E, Zheng C, Edner J, Ma D, Wood SM, Bechensteen AG, Boelens JJ, Celkan T, Farah RA, Hultenby K, Winiarski J, Roche PA, et al. Defective cytotoxic lymphocyte degranulation in syntaxin-11 deficient familial hemophagocytic lymphohistiocytosis 4 (FHL4) patients. Blood. 2007; 110:1906-1915.

38. Kang L, Sun J, Wen X, Cui J, Wang G, Hoffman AR, Hu JF, Li W. Aberrant allele-switch imprinting of a novel IGF1R intragenic antisense non-coding RNA in breast cancers. Eur J Cancer. 2015; 51:260-270.

39. Shi X, Li M, Cui M, Niu C, Xu J, Zhou L, Li W, Gao Y, Kong W, Cui J, Hu J, Jin H. Epigenetic suppression of the antitumor cytotoxicity of NK cells by histone deacetylase inhibitor valproic acid. Am J Cancer Res. 2016; 6:600-614.

40. Li T, Chen H, Li W, Cui J, Wang G, Hu X, Hoffman AR, $\mathrm{Hu}$ J. Promoter histone H3K27 methylation in the control of IGF2 imprinting in human tumor cell lines. Hum Mol Genet. 2014; 23:117-128. 